\title{
Identification of dihalogenated proteins in rat intestinal mucosa injured by indomethacin
}

\author{
Tomohisa Takagi, ${ }^{1}$ Yuji Naito, ${ }^{1, *}$ Hitomi Okada, ${ }^{1}$ Tetsuya Okayama, ${ }^{1}$ Katsura Mizushima, ${ }^{1}$ Shinya Yamada, ${ }^{1}$ \\ Kouhei Fukumoto, ${ }^{1}$ Ken Inoue, ${ }^{1}$ Megumi Takaoka, ${ }^{1}$ Tomoko Oya-Ito, ${ }^{1}$ Kazuhiko Uchiyama, ${ }^{1}$ Takeshi Ishikawa, ${ }^{1}$ \\ Osamu Handa, ${ }^{1}$ Satoshi Kokura, ${ }^{1}$ Nobuaki Yagi, ${ }^{1}$ Hiroshi Ichikawa, ${ }^{1}$ Yoji Kato, ${ }^{2}$ Toshihiko Osawa ${ }^{3}$ \\ and Toshikazu Yoshikawa'
}

${ }^{1}$ Molecular Gastroenterology and Hepatology, Graduate School of Medical Science, Kyoto Prefectural University of Medicine, Kyoto 602-8566, Japan ${ }^{2}$ School of Human Science and Environment, University of Hyogo, Himeji 670-0092, Japan

${ }^{3}$ Department of Nutritional Science, Aichi Gakuin University, Nisshin 470-0195, Japan

(Received 26 July, 2010; Accepted 4 August, 2010; Published online 26 February, 2011)

Previous studies have shown that activated neutrophils and their myeloperoxidase (MPO)-derived products play a crucial role in the pathogenesis of non-steroidal anti-inflammatory drug (NSAID)related small intestinal injury. The aim of the present study is to identify dihalogenated proteins in the small intestine on indomethacin administration. Intestinal damage was induced by subcutaneous administration of indomethacin $(10 \mathrm{mg} / \mathrm{kg})$ in male Wistar rats, and the severity of the injury was evaluated by measuring the area of visible ulcerative lesions. Tissue-associated MPO activity was measured in the intestinal mucosa as an index of neutrophil infiltration. The dihalogenated proteins were separated by two-dimensional polyacrylamide gel electrophoresis (2DPAGE) using novel monoclonal antibodies against dibromotyrosine (DiBrY), and they were identified by matrix-assisted laser desorption/ionization time-of-flight (MALDI-TOF) peptide mass fingerprinting and a Mascot database search. Single administration of indomethacin elicited increased ulcerative area and MPO activity in the small intestine. 2D-PAGE showed an increased level of DiBrY-modified proteins in the indomethacin-induced injured intestinal mucosa and 6 modified proteins were found. Enolase-1 and albumin were found to be DiBrY modified. These proteins may be responsible for the development of neutrophil-associated intestinal injury induced by indomethacin.

Key Words: indomethacin, dibromotyrosine, albumin, enolase

$\mathrm{N}$ on-steroidal anti-inflammatory drugs (NSAIDs) are commonly used world over for the treatment of musculoskeletal pain and inflammation. A major limitation of the clinical utility of NSAIDs is their gastrointestinal toxicity and the increased risk of serious, possibly fatal, complications of the upper gastrointestinal tract, including bleeding, ulceration, and perforation of the stomach and duodenum. ${ }^{(1-4)}$ Furthermore, recent advances in gastrointestinal endoscopies such as capsule endoscopy and balloon endoscopy for investigation of the entire small intestine have revealed that NSAIDs can cause mucosal injuries in the small intestine as well as a variety of abnormalities such as ulcerations, perforation, bleeding, and diaphragm-like strictures. ${ }^{(5,6)}$ Therefore, it is important to investigate the precise pathogenesis of NSAID-induced intestinal injuries and determine preventive and therapeutic strategies for them.

Investigations using experimental animal models have shown that NSAIDs such as indomethacin damage the small intestine. Increasing evidence suggests that the intestinal injury caused by indomethacin is associated with abnormal intestinal permeability, bacterial translocation, activation of inflammatory cytokines, nitric oxide (NO) overproduction, and prostaglandin deficiency, in addition to neutrophil accumulation. ${ }^{(7-11)}$ In particular, the infiltration of neutrophils into the intestinal mucosa may play a crucial role in the pathogenesis of NSAID-induced intestinal injury. Stadnyk et al. demonstrated that neutrophils were detectable in the small intestine of rats at $6 \mathrm{~h}$ after indomethacin administration and continued to accumulate until $48 \mathrm{~h}$ after administration. ${ }^{(12)}$ We also previously reported that neutrophil infiltration gradually increased in a time-dependent manner after indomethacin administration in rats. ${ }^{(7,13,14)}$ Interestingly, impaired leukocyte recruitment and neutrophil depletion resulted in the amelioration of NSAID-induced injury in mice. ${ }^{(15,16)}$ Thus, neutrophil-mediated inflammation can be considered to be involved in NSAID-induced intestinal injury.

On the other hand, neutrophils have granules containing peroxidases such as myeloperoxidase (MPO). MPO is known to catalyze the formation of hypochlorous acid $(\mathrm{HOCl})$ and hypobromous acid ( $\mathrm{HOBr})$ using hydrogen peroxide $\left(\mathrm{H}_{2} \mathrm{O}_{2}\right)$ and $\mathrm{Cl}^{-}$or $\mathrm{Br}^{-}$, respectively. These reactive intermediates may react with proteins, ${ }^{(17,18)}$ lipids,${ }^{(19,20)}$ and nucleotides, ${ }^{(21-23)}$ and they reportedly cause tyrosine halogenation; such halogenations give rise to products such as dibromotyrosine (DiBrY), ${ }^{(24,25)}$ which is a tyrosine molecule modified by bromine at the 3- and 5-positions and is one of the major oxidative products derived from neutrophil MPO.

The role of tyrosine halogenation in the development of neutrophil-mediated inflammatory damage such as NSAID-induced intestinal injuries remains unclear. In this study, we identified the DiBrY-modified proteins involved in indomethacin-induced intestinal injuries by using a proteomics-based approach.

\section{Materials and Methods}

Experimental animals. Male Wistar rats weighing 190-210 g were obtained from Shimizu Laboratory Supplies Co., Ltd. (Kyoto, Japan). The animals were housed at $22^{\circ} \mathrm{C}$ in a controlled environment with $12 \mathrm{~h}$ of artificial light per day, and they were allowed ad libitum access to rat chow and water. The experiments were performed on 5-6 non-fasting rats per group without anesthesia. Animal maintenance and all experimental procedures were carried out in accordance with the NIH guidelines for the use of experimental animals. All experimental protocols were approved by the Animal Care Committee of the Kyoto Prefectural University of Medicine (Kyoto, Japan).

Induction of small intestinal lesions. The animals were

*To whom correspondence should be addressed.

E-mail: ynaito@koto.kpu-m.ac.jp 
subcutaneously administered $10 \mathrm{mg} / \mathrm{kg}$ indomethacin (Sigma Chemical; St. Louis, MO) and killed $24 \mathrm{~h}$ later under deep ether anesthesia. To determine the extent of injury, 1\% Evans blue was injected intravenously 30 min before euthanasia; the jejunum and ileum were then removed, opened along the antimesenteric attachment, and examined for lesions under a dissecting microscope with square grids. The area (in $\mathrm{mm}^{2}$ ) of visible lesions was macroscopically measured, totaled per $20 \mathrm{~cm}$ of the small intestine, and expressed as an ulcer index. The degree of intestinal injury was evaluated by an independent observer who was blinded to the experimental conditions. For histological examination, formalin-fixed tissue was stained with hematoxylin and eosin (H\&E). Staining was evaluated by light microscopy by a pathologist who was also blinded to the experimental conditions.

Measurement of MPO activity. Tissue-associated MPO activity was determined by a modification of the method of Grisham et $a l^{(26)}$ as an index of neutrophil accumulation. The intestinal mucosa was scraped off using two glass slides and then homogenized with $1.5 \mathrm{ml}$ of $10 \mathrm{mmol} / \mathrm{l}$ potassium phosphate buffer ( $\mathrm{pH} \mathrm{7.8)} \mathrm{containing} 30 \mathrm{mmol} / \mathrm{l} \mathrm{KCl}$ in a Teflon PotterElvehjem homogenizer. The mucosal homogenates were centrifuged at $20,000 \times \mathrm{g}$ for $15 \mathrm{~min}$ at $4^{\circ} \mathrm{C}$ to pelletize the insoluble cellular debris. The pellet was then dissolved in an equivalent volume of $0.05 \mathrm{M}$ potassium phosphate buffer ( $\mathrm{pH} 5.4$ ) containing $0.5 \%$ hexadecyltrimethylammonium bromide. The samples were centrifuged at $20,000 \times g$ for $15 \mathrm{~min}$ at $4^{\circ} \mathrm{C}$ and the supernatants collected. MPO activity was assessed by measuring the $\mathrm{H}_{2} \mathrm{O}_{2}$ dependent oxidation of 3,3',5,5'-tetramethylbenzidine. One unit of enzyme activity was defined as the amount of MPO required to cause a $1.0 / \mathrm{min}$ change in absorbance of at $645 \mathrm{~nm}$ and $25^{\circ} \mathrm{C}$. The level of MPO activity in the mucosal homogenates was expressed as unit per milligram of protein. The total protein in the tissue homogenates was measured using a Bio-Rad Protein Assay kit (Bio-Rad Laboratories, KK; Tokyo, Japan) according to the manufacturer's protocol.

Sample preparation and two-dimensional polyacrylamide gel electrophoresis (2D-PAGE). The intestinal tissue samples $(200 \mathrm{mg})$ were homogenized in $2 \mathrm{ml}$ homogenization buffer (8 M urea, 4\% 3[(3-Cholamidopropyl)dimethylammonio]propanesulfonic acid (CHAPS), $40 \mathrm{mM}$ Tris) containing nuclease and protein inhibitors (GE Healthcare UK Ltd.; Buckinghamshire, England) using a homogenizer at $25,000 \mathrm{rpm}$. The homogenized samples were transferred to an ultracentrifuge tube, and the nucleic acids were removed by centrifugation $(20 \mathrm{~min}$ at $20,000 \times g$ and $25^{\circ} \mathrm{C}$ ). The samples were then precipitated using the PlusOne ${ }^{\mathrm{TM}}$ 2D Clean-Up kit as recommended by the manufacturer (GE Healthcare UK Ltd.). The protein concentration in the supernatant fraction was determined using the Bradford assay with bovine serum albumin as the standard.

The samples were solubilized in $6 \mathrm{M}$ urea, $20 \mathrm{mM}$ dithiothreitol, $30 \%$ glycerol, $45 \mathrm{mM}$ Tris base, $1.6 \%$ lithium dodecyl sulfate (LDS) (Invitrogen Japan KK, Tokyo, Japan), and $0.002 \%$ bromophenol blue and were subsequently heated at $70^{\circ} \mathrm{C}$ for $10 \mathrm{~min}$. Protein lysates $(50 \mu \mathrm{g})$ were separated by $2 \mathrm{D}$-PAGE. Immobilized $\mathrm{pH}$ gradient (IPG) strips of $\mathrm{pH} 4-7$ or $\mathrm{pH} 5.3-6.3$ (Invitrogen Japan KK) were rehydrated overnight with the protein samples. The proteins were separated on the basis of their respective isoelectric points by isoelectric focusing (IEF) using $\mathrm{ZOOM}^{\circledR}$ IPGRunner $^{\mathrm{TM}}$ (Invitrogen Japan KK) at a maximal voltage of $2000 \mathrm{~V}$ and a current limit of $50 \mu \mathrm{A}$ per gel. Following IEF, the IPG strips were incubated in equilibration buffer I $(6 \mathrm{M}$ urea, $130 \mathrm{mM}$ dithiothreitol, $30 \%$ glycerol, $45 \mathrm{mM}$ Tris base, $1.6 \%$ LDS, $0.002 \%$ bromophenol blue; Genomic Solutions) and once in equilibration buffer II (6 M urea, $135 \mathrm{mM}$ iodoacetamide, $30 \%$ glycerol, $45 \mathrm{mM}$ Tris base, $1.6 \%$ LDS, $0.002 \%$ bromphenol blue; Genomic Solutions) for 15 min each. The equilibrated IPG strips were applied to $4-12 \%$ Bis-Tris gradient gels (Invitrogen Japan $\mathrm{KK}$ ), and the NuPAGE ${ }^{\circledR}$ MOPS buffer (Invitrogen Japan KK) was used at $200 \mathrm{~V}$ for $55 \mathrm{~min}$ to separate the proteins in the second dimension on the basis of their molecular size. Following electrophoresis, the gels were transferred onto nitrocellulose and immunoblotted with the anti-DiBrY monoclonal antibody (3A5), which was kindly gifted to us by Prof. Toshihiko Osawa. ${ }^{(24)}$

In-gel protein digestion and peptide mass fingerprinting. Protein spots of interest were excised using Xcise Proteomics Systems (Shimadzu Corp., Kyoto, Japan) from the preparative gel stained with Deep Purple ${ }^{\mathrm{TM}}$ Total Protein Stain (GE Healthcare UK Ltd). The excised spots were washed thrice with $50 \mathrm{mmol} / 1$ ammonium bicarbonate and $50 \%$ acetonitrile $(\mathrm{ACN})$, dehydrated with $100 \% \mathrm{ACN}$. The proteins were subjected to in-gel digestion with $10 \mu \mathrm{g} / \mathrm{ml}$ trypsin (Promega KK; Tokyo, Japan) in $50 \mathrm{mmol} / 1$ ammonium bicarbonate at $30^{\circ} \mathrm{C}$ overnight. Tryptic peptides were extracted from the gel slices with $1 \%$ trifluoracetic acid and 50\% ACN. After concentration and desalting using a Millipore ZipTip $\mu$-C18 (Nihon Millipore KK; Tokyo, Japan), the resulting peptides were mixed with an equal volume of $10 \mathrm{mg} / \mathrm{ml}$ 2,5-dihydroxybenzoic acid (DHBA), and the peptide mass spectra were obtained using the AXIMA-QIT ${ }^{\mathrm{TM}}$ MALDITOF-MASS (Shimadzu) platform for peptide mass fingerprinting. Protein identification was carried out using the Mascot search engine (http://www.matrixscience.com/search_form_select.html).

Statistical analysis. Results are presented as the mean \pm (standard error of the mean [SEM]). Overall differences between groups were determined by one-way analysis of variance (ANOVA). Whenever the one-way ANOVA was significant, differences between individual groups were analyzed by Bonferroni's multiple comparisons test. Differences of $p<0.05$ were considered significant. All analyses were performed using the GraphPad Prism 4 program (GraphPad Software Inc.; San Diego, CA) for Macintosh.

\section{Results}

Intestinal ulceration after indomethacin administration. A single administration of $10 \mathrm{mg} / \mathrm{kg}$ indomethacin elicited multiple erosions in the small intestine (Fig. 1B); a normal untreated small intestine is shown in Fig. 1A for comparison. The ulcer index gradually increased with time, and significant increases in this index were noted 6,12 , and $24 \mathrm{~h}$ after indomethacin administration (Fig. 1C).

Histological findings and time course of changes in MPO activites. The histological features observed were defects of the villi, epithelial stratification, basal lamina degeneration, and infiltration of the mucosa by inflammatory cells (neutrophils) (Fig. 2B); none of these were observed in the normal intestinal
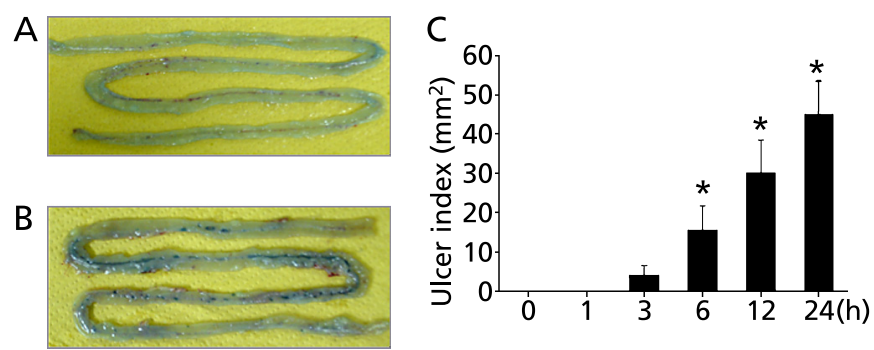

Fig. 1. Representative macroscopic findings and ulcer index after indomethacin administration. To determine the extent of intestinal injury, 1\% Evans blue was injected intravenously $30 \mathrm{~min}$ before euthanasia. The representative macroscopic findings indicate that the small intestinal injuries were induced $24 \mathrm{~h}$ after indomethacin administration (B); a normal untreated intestine is shown in (A). The ulcer index after indomethacin administration was evaluated as described in Materials and Methods (C). Data represent the mean \pm (SEM) of 7 rats. ${ }^{*} p<0.01$ compared to the sham group $(0 \mathrm{~h})$. 


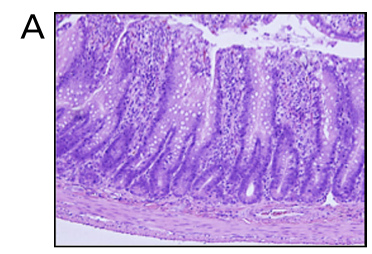

B
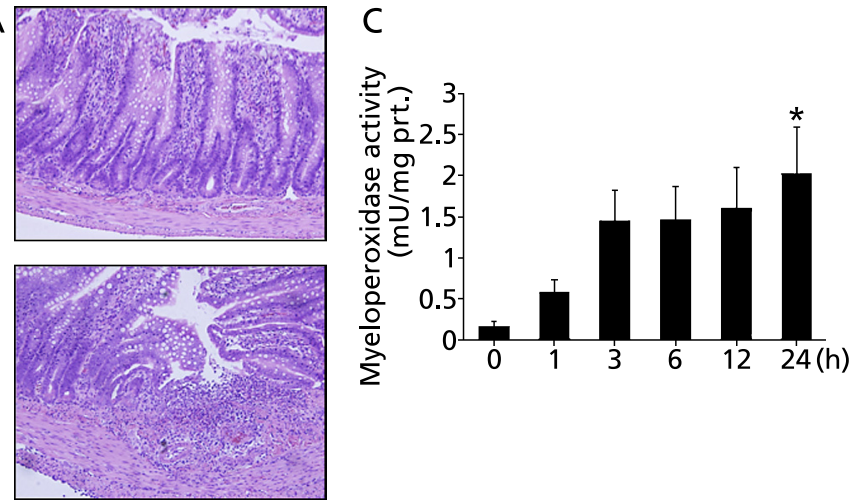

Fig. 2. Representative histological findings and neutrophil accumulation in the intestinal mucosa after indomethacin administration. Histological appearance of the intestinal tissue of the sham group rats (A) and rats treated with indomethacin (B). Histological examination revealed that indomethacin administration induced ulceration in the small intestine, which was associated with the infiltration of numerous inflammatory cells. Hematoxylin and eosin (H\&E) staining $(\times 40)$. The time course of tissue-associated myeloperoxidase (MPO) activity after indomethacin administration was determined as an index of neutrophil accumulation in the intestinal mucosa (C). Data represent the mean \pm (SEM) of 8 rats. ${ }^{\star} p<0.05$ compared to the sham group $(0 \mathrm{~h})$.

mucosa (Fig. 2A). Neutrophil accumulation was evaluated by measuring the MPO activity in the intestinal mucosa homogenates. The MPO activity in the intestinal mucosa was markedly increased by indomethacin treatment and the increase was significant $24 \mathrm{~h}$ after administration (Fig. 2C).

Identification of DiBrY-modified proteins in intestinal mucosa with indomethacin-induced injury. To evaluate the expression of DiBrY-modified proteins in the intestinal mucosa, we performed 2D-PAGE by using a pH 4-7 IPG strip and 4-12\% Bis-Tris gradient gels. Fig. 3 (upper panel; A, B) shows individual proteins separated by 2D-PAGE and stained with Deep Purple ${ }^{\mathrm{TM}}$ Total Protein Stain. Subsequently, the gels were transferred onto nitrocellulose and were immunoblotted with anti-DiBrY monoclonal antibody (Fig. 3, lower panel; C, D). We focused on analyzing DiBrY-modified proteins between pI 5.3 and 6.3 of size between 20 and $60 \mathrm{kDa}$. (Fig. 3, lower panel, boxed image).

Next, the individual proteins were separated by 2D-PAGE between pI 5.3 and 6.3 (Fig. 4). As shown in Fig. 4B, the immunoblot analysis revealed 6 DiBrY-modified proteins (indicated by arrows). These 6 proteins were analyzed by MALDITOF using peptide-mass fingerprinting, and a database search was performed with Mascot (Table 1). Enolase-1 and albumin were found to be DiBrY-modified in the intestinal mucosa with indomethacin-induced injury.

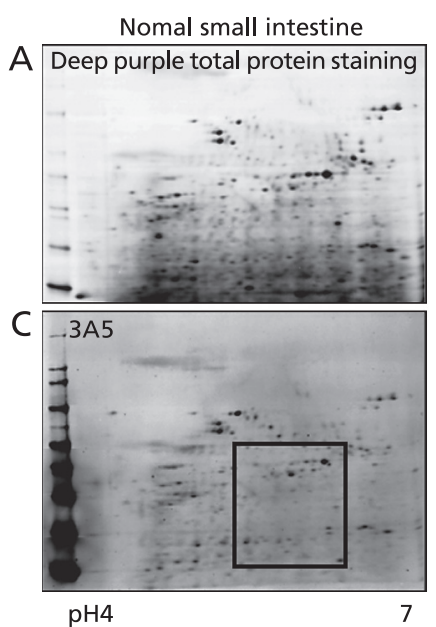

NSAID-induced injured intestine
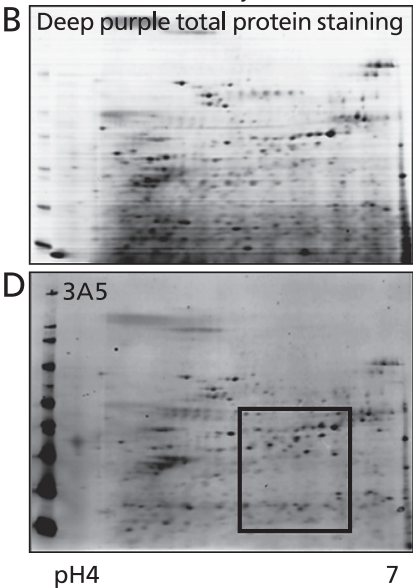

Fig. 3. Image of 2D-PAGE analytical gels and immunoblotting with anti-dibromotyrosine (DiBrY) monoclonal antibody. (A, B) 2D-PAGE gels were stained using Deep Purple ${ }^{\mathrm{TM}}$ Total Protein Stain. Subsequently, they were transferred onto nitrocellulose and immunoblotted with the anti-DiBrY monoclonal antibody (C, D). Boxes mark image areas that were investigated in subsequent experiments at $\mathrm{pH}$ 5.3-6.3.
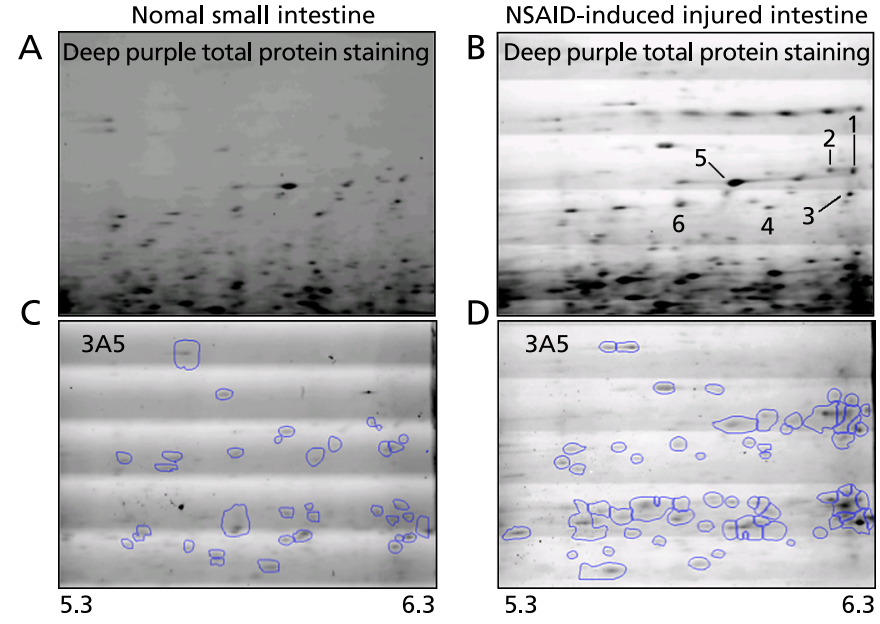

Fig. 4. Image of 2D-PAGE between pH 5.3 and 6.3. (A, B) 2D-PAGE between $\mathrm{pH}^{5.3}$ and 6.3 gels were stained using Deep Purple ${ }^{\mathrm{TM}}$ Total Protein Stain. (C, D) Immunoblotting analysis revealed 6 DiBrY-modified proteins (arrows) in the intestinal mucosa injured by indomethacin treatment.

Table 1. List of dibromotyrosine-modified proteins identified in indomethacin-induced injured intestinal mucosa

\begin{tabular}{clcccc}
\hline Spot No. & Protein identity & pl & MW (Da) & $\begin{array}{c}\text { MASCOT } \\
\text { score }\end{array}$ & $\begin{array}{c}\text { Sequence } \\
\text { coverage (\%) }\end{array}$ \\
\hline 1 & enolase-1 & 6.16 & 47440 & 78 & 29 \\
2 & enolase-1 & 6.16 & 47440 & 58 & 32 \\
3 & Albumin isoform CRA_a & 6.72 & 53060 & 70 & 21 \\
4 & Albumin isoform CRA_a & 6.72 & 53060 & 93 & 34 \\
5 & Albumin isoform CRA_a & 6.72 & 53060 & 119 & 46 \\
6 & Albumin isoform CRA_a & 6.72 & 53060 & 82 & 23 \\
\hline
\end{tabular}

pl, Isoelectric point: MW, Molecular Weight.

MASCOT score described the significance of the search results from the search engine MASCOT and a significance threshold of about 60 is typical. The sequence coverage was defined as the ratio of the number of the identified amino acids to the total number acid of the protein (\%). 


\section{Discussion}

In this study, we performed 2D-PAGE to identify DiBrYmodified proteins in intestinal mucosa injured because of indomethacin. We confirmed that 2 proteins (enolase- 1 and albumin) exhibited altered expression, as shown in Table 1. It is well known that albumin possesses potent antioxidant properties and nonspecifically binds to free radicals, ${ }^{(27,28)}$ Enolase- 1 modification has also been reported in many reports. ${ }^{(29-33)}$ The present proteome analysis might provide important, novel clues for understanding NSAID-induced intestinal injuries and reveal candidates for therapeutic targets.

Enolase, also known as phosphopyruvate dehydratase, is a glycolytic enzyme. Mammalian enolase has 3 isoforms: enolase- 1 ( $\alpha$-enolase), enolase-2 ( $\gamma$-enolase), and enolase-3 ( $\beta$-enolase). The expression of these isoforms is developmentally regulated in a tissue-specific manner. Enolase-1 is widely distributed in a variety of tissues, whereas enolase- 2 and enolase- 3 are found exclusively in neurons or neuroendocrine tissue and muscle tissues, respectively. ${ }^{(34)}$ Interestingly, recent investigations have revealed that enolase enzymes possess various different regulatory properties in addition to their role in glycolysis and glucogenesis. Enolase-1 plays a key role in anerobic metabolism and acts as a plasminogen receptor (Plg-Rs), ${ }^{(35)}$ indicating that it may play a role in tissue invasion. In fact, the enhanced binding and activation of plasminogen by neoplastic cells has been attributed to enhanced enolase- 1 expression, and abnormal expression of enolase- 1 is associated with tumor progression in lung cancer. ${ }^{(36-38)}$ These findings collectively indicate that, enolase- 1 may be a potential therapeutic target for cancer. Further, although the role of enolase1 remains unclear in intestinal inflammation, Wygrecka et al.

\section{References}

1 Allison MC, Howatson AG, Torrance CJ, Lee FD, Russell RI. Gastrointestinal damage associated with the use of nonsteroidal antiinflammatory drugs. $N$ Engl J Med 1992; 327: 749-754.

2 Fries JF, Williams CA, Bloch DA, Michel BA. Nonsteroidal anti-inflammatory drug-associated gastropathy: incidence and risk factor models. Am J Med 1991; 91: 213-222.

3 Naito Y, Iinuma S, Yagi N, and et al. Prevention of indomethacin-induced gastric mucosal injury in helicobacter pylori-negative healthy volunteers: a comparison study rebamipide vs famotidine. J Clin Biochem Nutr 2008; 43: 34-40.

4 Park SH, Cho CS, Lee OY, and et al. Comparison of prevention of NSAIDinduced gastrointestinal complications by rebamipide and misoprostol: a randomized, multicenter, controlled trial-STORM STUDY. J Clin Biochem Nutr 2007; 40: 148-155.

5 Matsumoto T, Kudo T, Esaki M, and et al. Prevalence of non-steroidal anti-inflammatory drug-induced enteropathy determined by double-balloon endoscopy: a Japanese multicenter study. Scand J Gastroenterol 2008; 43: 490-496.

6 Higuchi K, Umegaki E, Watanabe T, and et al. Present status and strategy of NSAIDs-induced small bowel injury. J Gastroenterol 2009; 44: 879-888.

7 Harusato A, Naito Y, Takagi T, and et al. Inhibition of Bach1 ameliorates indomethacin-induced intestinal injury in mice. J Physiol Pharmacol 2009; 60 Suppl 7: 149-154.

8 Higuchi K, Yoda Y, Amagase K, and et al. Prevention of NSAID-induced small intestinal mucosal injury: prophylactic potential of lansoprazole. J Clin Biochem Nutr 2009; 45: 125-130.

9 Weissenborn U, Maedge S, Buettner D, Sewing KF. Indometacin-induced gastrointestinal lesions in relation to tissue concentration, food intake and bacterial invasion in the rat. Pharmacology 1985; 30: 32-39.

10 Whittle BJ. Temporal relationship between cyclooxygenase inhibition, as measured by prostacyclin biosynthesis, and the gastrointestinal damage induced by indomethacin in the rat. Gastroenterology $1981 ; \mathbf{8 0}$ : 94-98.

11 Whittle BJ, László F, Evans SM, Moncada S. Induction of nitric oxide synthase and microvascular injury in the rat jejunum provoked by indomethacin. Br J Pharmacol 1995; 116: 2286-2290. demonstrated that lipopolysaccharide (LPS) induced the expression of enolase-1 in monocytes, and the increased cell-surface expression of enolase-1 mediated the invasion of inflammatory cells. ${ }^{(39)}$

In proteomics studies, enolase-1 has been frequently identified to be differentially expressed in 2D-PAGE-based experiments on human and animal tissues. In particular, enolase- 1 was found to be excessively carbonylated, ${ }^{(30,31)}$ nitrated, ${ }^{(33)}$ and 4-hydroxynonenal (HNE)-modified ${ }^{(29,32)}$ in various diseases. In the present study, we identified DiBrY-modified enolase-1 in indomethacin-induced intestinal injury. Although further studies on the precise function of DiBrY-modified enolase-1 are required, the protein may be considered to play an important role in the pathogenesis of intestinal inflammation.

In conclusion, we identified DiBrY-modified proteins, enolase-1 and albumin, in intestinal tissue with indomethacin-induced injury. Although further examination is required to gain a better understanding of the role of these modified proteins, DiBrY is expected to be a novel biomarker for inflammation-related tissue damage and may be involved in neutrophil accumulation.

\section{Acknowledgments}

This work was supported by a Grant-in-Aid for Scientific Research (B) to T.Y. (no. 21390184) and Scientific Research (C) to Y.N. (no. 22590705), by a City Area Program to T.Y. and Y.N. from Ministry of Education, Culture, Sports, Science and Technology, Japan, and by a Adaptable and Seamless Technology Transfer Program through target-driven R\&D to Y.N. from Japan Science and Technology Agency.

12 Stadnyk AW, Dollard C, Issekutz TB, Issekutz AC. Neutrophil migration into indomethacin induced rat small intestinal injury is CD11a/CD18 and CD11b/ CD18 co-dependent. Gut 2002; 50: 629-635.

13 Kuroda M, Yoshida N, Ichikawa H, and et al. Lansoprazole, a proton pump inhibitor, reduces the severity of indomethacin-induced rat enteritis. Int J Mol Med 2006; 17: 89-93.

14 Okuda T, Yoshida N, Takagi T, and et al. CV-11974, angiotensin II type I receptor antagonist, reduces the severity of indomethacin-induced rat enteritis. Dig Dis Sci 2008; 53: 657-663.

15 Beck PL, Xavier R, Lu N, and et al. Mechanisms of NSAID-induced gastrointestinal injury defined using mutant mice. Gastroenterology 2000; 119: 699-705.

16 Watanabe T, Higuchi K, Kobata A, and et al. Non-steroidal anti-inflammatory drug-induced small intestinal damage is Toll-like receptor 4 dependent. Gut 2008; 57: 181-187.

17 Domigan NM, Charlton TS, Duncan MW, Winterbourn CC, Kettle AJ. Chlorination of tyrosyl residues in peptides by myeloperoxidase and human neutrophils. J Biol Chem 1995; 270: 16542-16548.

18 Hazen SL, Hsu FF, Mueller DM, Crowley JR, Heinecke JW. Human neutrophils employ chlorine gas as an oxidant during phagocytosis. J Clin Invest 1996; 98: 1283-1289.

19 Albert CJ, Thukkani AK, Heuertz RM, Slungaard A, Hazen SL, Ford DA. Eosinophil peroxidase-derived reactive brominating species target the vinyl ether bond of plasmalogens generating a novel chemoattractant, alphabromo fatty aldehyde. J Biol Chem 2003; 278: 8942-8950.

20 Thukkani AK, Albert CJ, Wildsmith KR, and et al. Myeloperoxidase-derived reactive chlorinating species from human monocytes target plasmalogens in low density lipoprotein. J Biol Chem 2003; 278: 36365-36372.

21 Henderson JP, Byun J, Heinecke JW. Molecular chlorine generated by the myeloperoxidase-hydrogen peroxide-chloride system of phagocytes produces 5-chlorocytosine in bacterial RNA. J Biol Chem 1999; 274: 33440-33448.

22 Shen Z, Mitra SN, Wu W, and et al. Eosinophil peroxidase catalyzes bromination of free nucleosides and double-stranded DNA. Biochemistry 2001; 40: 2041-2051.

23 Masuda M, Suzuki T, Friesen MD, and et al. Chlorination of guanosine and 
other nucleosides by hypochlorous acid and myeloperoxidase of activated human neutrophils. Catalysis by nicotine and trimethylamine. $\mathrm{J}$ Biol Chem 2001; 276: 40486-40496.

24 Kato Y, Kawai Y, Morinaga H, and et al. Immunogenicity of a brominated protein and successive establishment of a monoclonal antibody to dihalogenated tyrosine. Free Radic Biol Med 2005; 38: 24-31.

$25 \mathrm{Wu} \mathrm{W}$, Chen Y, d'Avignon A, Hazen SL. 3-Bromotyrosine and 3,5dibromotyrosine are major products of protein oxidation by eosinophil peroxidase: potential markers for eosinophil-dependent tissue injury in vivo. Biochemistry 1999; 38: 3538-3548.

26 Grisham MB, Hernandez LA, Granger DN. Xanthine oxidase and neutrophil infiltration in intestinal ischemia. Am J Physiol 1986; 251: G567-G574.

27 Kouoh F, Gressier B, Luyckx M, and et al. Antioxidant properties of albumin: effect on oxidative metabolism of human neutrophil granulocytes. Farmaco 1999; 54: 695-699.

28 Guedes S, Vitorino R, Domingues R, Amado F, Domingues P. Oxidation of bovine serum albumin: identification of oxidation products and structural modifications. Rapid Commun Mass Spectrom 2009; 23: 2307-2315.

29 Gentile F, Pizzimenti S, Arcaro A, and et al. Exposure of HL-60 human leukaemic cells to 4-hydroxynonenal promotes the formation of adduct(s) with alpha-enolase devoid of plasminogen binding activity. Biochem J 2009; 422: 285-294.

30 Kumagai A, Nakayashiki N, Aoki Y. Analysis of age-related carbonylation of human vitreous humor proteins as a tool for forensic diagnosis. Leg Med (Tokyo) 2007; 175-180.

31 Lii CK, Lin AH, Lee SL, Chen HW, Wang TS. Oxidative modifications of proteins by sodium arsenite in human umbilical vein endothelial cells. Environ Toxicol 2010 [Epub ahead of print].

32 Reed TT, Pierce WM, Markesbery WR, Butterfield DA. Proteomic identification of HNE-bound proteins in early Alzheimer disease: Insights into the role of lipid peroxidation in the progression of AD. Brain Res 2009; 1274: 66-76.

33 Sultana R, Poon HF, Cai J, and et al. Identification of nitrated proteins in Alzheimer's disease brain using a redox proteomics approach. Neurobiol Dis 2006; 22 : 76-87.

34 Pancholi V. Multifunctional alpha-enolase: its role in diseases. Cell Mol Life Sci 2001; 58: 902-920.

35 Miles LA, Dahlberg CM, Plescia J, Felez J, Kato K, Plow EF. Role of cellsurface lysines in plasminogen binding to cells: identification of alphaenolase as a candidate plasminogen receptor. Biochemistry 1991; 30: 1682 1691.

36 Jankowska R, Witkowska D, Porebska I, Kuropatwa M, Kurowska E, Gorczyca WA. Serum antibodies to retinal antigens in lung cancer and sarcoidosis. Pathobiology 2004; 71: 323-328.

37 Li C, Xiao Z, Chen Z, and et al. Proteome analysis of human lung squamous carcinoma. Proteomics 2006; 6: 547-558.

38 Chang GC, Liu KJ, Hsieh CL, and et al. Identification of alpha-enolase as an autoantigen in lung cancer: its overexpression is associated with clinical outcomes. Clin Cancer Res 2006; 12: 5746-5754.

39 Wygrecka M, Marsh LM, Morty RE, and et al. Enolase-1 promotes plasminogen-mediated recruitment of monocytes to the acutely inflamed lung. Blood 2009; 113: 5588-5598. 